\title{
Synaptic activity and bioenergy homeostasis: implications in brain trauma and neurodegenerative diseases
}

\author{
Natasha Khatri ${ }^{1,2}$ and Heng-Ye Man ${ }^{1,2 *}$ \\ 1 Department of Biology, Boston University, Boston, MA, USA \\ ${ }^{2}$ Department of Pharmacology and Experimental Therapeutics, Boston University School of Medicine, Boston, MA, USA
}

\section{Edited by:}

Guogiang Xing, Lotus Biotech.com, Gaithersburg, USA

\section{Reviewed by:}

Amade Bregy, University of Miami, USA

John Anagli, Banyan Biomarkers Inc. USA

\section{*Correspondence}

Heng-Ye Man, Department of Biology,

Boston University, 5 Cummington

Mall, Boston, MA 02215, USA

e-mail: hman@bu.edu
Powered by glucose metabolism, the brain is the most energy-demanding organ in our body. Adequate ATP production and regulation of the metabolic processes are essential for the maintenance of synaptic transmission and neuronal function. Glutamatergic synaptic activity utilizes the largest portion of bioenergy for synaptic events including neurotransmitter synthesis, vesicle recycling, and most importantly, the postsynaptic activities leading to channel activation and rebalancing of ionic gradients. Bioenergy homeostasis is coupled with synaptic function via activities of the sodium pumps, glutamate transporters, glucose transport, and mitochondria translocation. Energy insufficiency is sensed by the AMP-activated protein kinase (AMPK), a master metabolic regulator that stimulates the catalytic process to enhance energy production. A decline in energy supply and a disruption in bioenergy homeostasis play a critical role in multiple neuropathological conditions including ischemia, stroke, and neurodegenerative diseases including Alzheimer's disease and traumatic brain injuries.

Keywords: glucose metabolism, glutamatergic neurotransmission, AMPK, mitochondria, Alzheimer disease, traumatic brain injury, stroke

\section{INTRODUCTION}

The brain is the most energy-demanding organ in our body. It consumes $20 \%$ oxygen and $25 \%$ of total glucose supply, equivalent to approximately $20 \%$ of total ATP production (1-5). Given that the brain accounts for only $2 \%$ of our body weight, its energy consumption is impressive -10 times that of other organs on average. The high cost in energy is not solely due to a large number of cells in the brain, with an estimated 100 billion neurons and many fold more glia, because organs with a comparable number of cells such as the liver have a much more modest energy bill (6). In contrast to peripheral tissues, neurons depend almost entirely on glucose for ATP production (1). Notably, the brain lacks cellular mechanisms to store energy or energy-generating sources such as glycogen or fat. Rather, energy must be produced continuously in order to maintain neuronal activity. Therefore, neurons are extremely sensitive to energy decline occurring during hypoxia, ischemia, stroke, and other forms of neurotrauma. Indeed, decreased glucose metabolism and mitochondrial energy production dysfunction have been associated with neurodegenerative diseases such as Alzheimer's, Parkinson's, and Huntington's disease. Alzheimer's and Huntington's patients exhibit reduced glucose energy metabolism even at early stages of disease, possibly caused by reduced glucose uptake through transporters, mitochondrial dysfunction, or changes in mitochondrial motility. Traumatic brain injuries are becoming increasingly concerning in populations due to recent wars and the discovery of Chronic Traumatic Encephalopathy (CTE) in athletes. These conditions also cause rapid declines in neuronal glucose levels and associated long-term damaging effects, such as increased intracellular calcium, production of free radicals, and depolarization of the mitochondrial membrane. Recent studies have elucidated mechanisms in energy sensing and the role of synaptic events in energy metabolism and neuronal energy homeostasis, which shed light on our understanding of the pathogenesis of neurological diseases. In addition, proteins and pathways involved in neuronal energy metabolism are being investigated as therapeutic targets for neurodegenerative diseases and traumatic brain injuries.

\section{GLUTAMATERGIC EXCITATORY SYNAPTIC TRANSMISSION IS A PRIMARY ENERGY-CONSUIMING EVENT}

Although glia outnumber neurons, the latter account for $85 \%$ of energy consumption (1). Among many neuronal cellular events, action potential-mediated neuronal communication is believed to be a major process of energy consumption. However, in contrast to a long-held belief, recent studies have revealed that the propagation of action potentials is highly energy efficient (7), consuming only $11 \%$ of brain ATP (8). Instead, energy cost mainly comes from synaptic activity, including transmitter release, but primarily postsynaptic receptor activation (9). In the brain, most of the synaptic activity is mediated by glutamate, thus, the excitatory glutamatergic system represents the single largest energy consumer, consuming $50 \%$ of ATP in the brain $(4,8,10,11)$. In addition to glutamate receptor channel activity, other glutamate-related events including glutamate synthesis, vesicle filling, release, uptake, and recycling, as well as receptor trafficking and signaling, are also energy consuming.

At the presynaptic terminals, glutamate is enriched in synaptic vesicles (SVs), powered indirectly by a proton pump on the vesicle membrane, at a concentration of $100 \mathrm{mM}$. During synaptic 
transmission, a single vesicle release can cause a rapid rise of glutamate in the synaptic cleft to concentrations as high as $1 \mathrm{mM}$ (12). Under normal conditions, ambient glutamate in the extracellular environment is maintained by the constant activity of glutamate transporters at the plasma membrane of both neurons and glia $(12,13)$. Glial transporters often surround synapses to ensure an efficient uptake of released transmitter and prevent glutamate spillover.

There are three types of ligand-gated ionotropic glutamate receptors, including AMPA receptors (AMPARs), NMDA receptors (NMDARs), and kainate receptors (KRs) (14-16). AMPARs are sodium channels that are the major components responsible for synaptic transmission, whereas NMDARs play an essential role in the formation of synaptic plasticity, mainly via regulation of AMPAR trafficking and synaptic localization. More importantly, the high permeability of NMDARs to calcium enables the receptor to initiate a series of calcium-dependent signaling cascades, including those for energy-dependent protein modification and metabolic regulations (17). Of note, although NMDARs show high permeability to calcium and are often mistakenly considered a calcium channel, more than $80 \%$ of NMDA currents are actually carried by sodium (18). Since NMDA synaptic currents have a long-lasting time course compared to that of AMPARs, NMDARs contribute a large amount of sodium influx during synaptic activities.

A large amount of energy consumption results from the maintenance of ionic gradients via the sodium pump. Neuronal activity and synaptic transmission cause rises in intracellular sodium. Compared with the intracellular sodium concentration of about $10 \mathrm{mM}$ at resting conditions, an action potential can increase spine sodium concentrations to $35-40 \mathrm{mM}$, and tetanus stimulation for the induction of long-term potentiation $(100 \mathrm{~Hz}$ stimulation for $1 \mathrm{~s}$ ) leads to sodium levels as high as $100 \mathrm{mM}$ in the spine (19). Inhibition of the sodium pump activity abolishes glutamate-induced ATP reduction (20), indicating the sodium pump as the major cellular machinery attributing to glutamaterelated energy spending. Membrane depolarization by glutamate stimulation induces firing of action potentials, which also leads to sodium influx via voltage-gated sodium channels. However, consistent with the notion that action potentials are energy efficient, blockage of sodium channels by tetrodotoxin (TTX) does not affect glutamate-induced ATP reduction, indicating that glutamate receptors are the primary source of intracellular sodium.

\section{SENSING OF CELLULAR ENERGY BY AMPK SIGNALING}

When ATP is hydrolyzed to release energy to enable cellular processes, a rise in the AMP:ATP ratio is sensed by the bioenergy detector AMP-activated protein kinase (AMPK). Once activated, AMPK utilizes its serine/threonine kinase activity to increase the rate of cellular catabolism (glucose utilization, fatty acid oxidation, etc.) while simultaneously inhibiting anabolic processes (cell biosynthesis), resulting in a net increase in ATP production. AMPK is a heterotrimeric protein composed of $\alpha, \beta$, and $\gamma$ subunits in equal stoichiometry. The $\alpha$ subunit constitutes the catalytic domain, conferring kinase activity, while the $\gamma$ subunit enables AMPK to monitor cellular energy status through two AMP/ATP binding domains, referred to as Bateman domains, that bind AMP or ATP in a mutually exclusive manner (21-23). An increase in the concentrations of AMP, an indicator of energy insufficiency, will facilitate AMP binding to the AMPK Bateman domains, leading to a change in molecular structure, and exposure of an activation loop in the $\alpha$ subunit. This conformational alteration allows AMPK to be phosphorylated at the $\alpha$ subunit Threonine 172 residue by upstream kinases, causing a 50-100fold increase in the catalytic activity of AMPK (24). Conversely, a high concentration of intracellular ATP promotes ATP/Bateman domain binding and produces an antagonistic effect on AMPK activation. Given that neurons have a high degree of metabolic activity and energy demand, it is expected that AMPK plays a critical role in maintaining energy homeostasis within the brain.

AMPK can be phosphorylated by two upstream kinases including liver kinase $\mathrm{B} 1$ (LKB1) and the calmodulin-dependent protein kinase kinases, CaMKK $\alpha$, and CaMKK $\beta$ (25-28). LKB1 was originally found as the tumor suppressor mutated in the genetically inherited susceptibility to human cancer, coined Peutz-Jeghers Syndrome (PJS) (29). In peripheral tissues, LKB1 has been shown to be necessary for AMPK phosphorylation and activation (30, 31). Despite both LKB1 and AMPK being ubiquitously expressed in mammalian cells, there is evidence to suggest that AMPK may be acted upon by different AMPKKs in a tissue-specific manner. For instance, LKB1 has been demonstrated to be the major upstream activator of AMPK in muscle and liver cells $(32,33)$, however a study utilizing LKB1 knockouts found that LKB1 deficient neurons had similar levels of phosphorylated AMPK as compared to wild-type cells under normal physiological conditions (34). In neurons, AMPK is more likely to be regulated by calcium-dependent signaling. In rat brain slices, intracellular increases in $\mathrm{Ca}^{2+}$ results in CaMKK-dependent AMPK phosphorylation. Importantly, membrane depolarization causes AMPK phosphorylation in the absence of an obvious change in cellular AMP:ATP ratio, indicating that AMPK can be regulated in a $\mathrm{Ca}^{2+}$. dependent, AMP-independent manner (35). Thus, glutamatergic synaptic activity can signal neurons for energy production via calcium-mediated AMPK activation.

\section{COUPLING OF SYNAPTIC ACTIVITY AND ENERGY HOMEOSTASIS}

In the brain, glutamate is the major neurotransmitter mediating most synaptic transmission. Multiple molecular events occurring during synaptic activation, including sodium pump activity, receptor trafficking, cytoskeletal rearrangements, signaling, and metabolic processes make synaptic activity an energetically costly process (8). Thus, coordinated cellular processes are necessary to convey synaptic signals to bioenergy metabolic activities (Figure 1).

\section{CO-ORDINATION OF SODIUM PUMP AND GLUTAMATE RECEPTOR LOCALIZATION}

The sodium gradient forms the foundation for synaptic transmission and neuronal excitation. Because of the frequent perturbation of ion homeostasis due to constant neuronal activity, the workload of the $\mathrm{Na}^{+} / \mathrm{K}^{+}$ATPase (NKA) is so high that it consumes nearly half of the ATP in the brain. NKA is a heterodimer composed of 


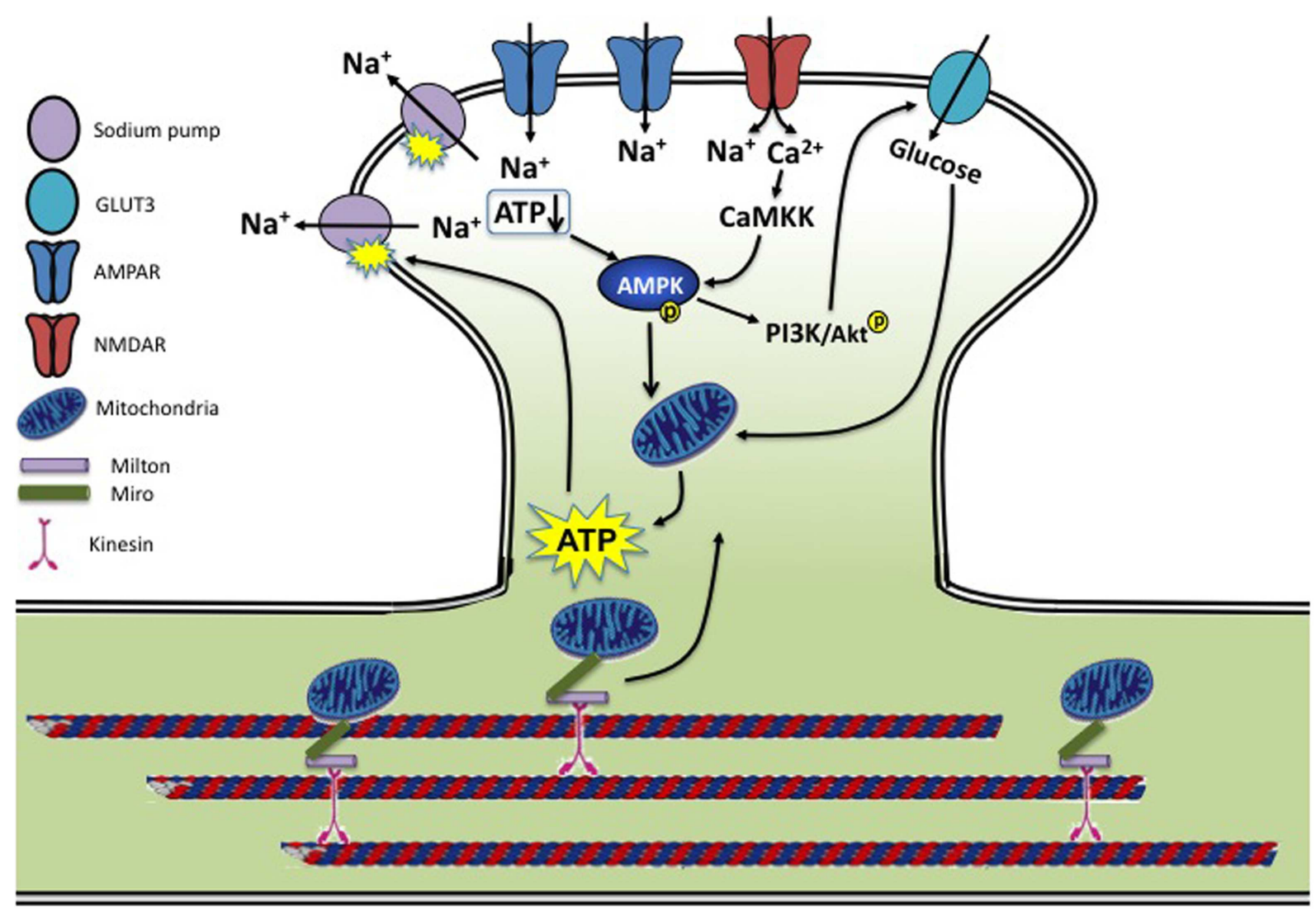

FIGURE 1 | Synaptic activity and energy homeostasis. During synaptic transmission, activation of glutamate receptors allows influx of a large amount of sodium and calcium. Rises in intracellular sodium are rebalanced by the sodium pump powered by ATP consumption. Cellular energy status is sensed by AMPK via a reduced ATP/AMP ratio and CaMKK-dependent calcium signaling, leading to enhanced mitochondria activity and ATP biogenesis. AMPK activity also activates the PI3K/AKT pathway, leading to enhanced glucose uptake by stimulating glucose transporter membrane expression and transport efficiency. Mitochondria are trafficked on microtubules into metabolically demanding synapses by binding to
Milton/Miro-mediated kinesin motor complex. In conditions of neurotrauma and neurodegenerative diseases, several aspects of this regulation may be disrupted. During hypoxia, ischemia, and stroke, insufficient ATP levels cause dysfunction of the sodium pump, leading to a loss in membrane potential and neuronal function. AD brains show reduced levels of GLUT3, and both AD and $\mathrm{HD}$ brains have a reduced rate of neuronal glucose metabolism. Mouse models of AD and PD show mitochondrial dysfunction along with reduced mitochondrial motility, preventing proper mitochondria delivery to the synapse and leading to decreased energy metabolism. Brains of traumatic injuries show reduced ATP levels and suppressed mitochondrial function. two subunits: the catalytic $\alpha$ subunit that contains ATPase activity and the regulatory $\beta$ subunit that is required for the enzymatic activity of NKA. At the single-neuron level, immunostainings have shown widespread localization of NKA in the soma and the dendrites $(36,37)$. During synaptic transmission, AMPAR-mediated currents are carried by sodium ions that flow into the cytosol of the neuron, typically within a microspace of the spine $<1 \mu \mathrm{m}^{3}$. In hippocampal neurons, one action potential can cause a severalfold increase in intraspinal sodium. The frequent and often large rises in intraspinal sodium must be exuded efficiently in order to maintain synapse electrophysiology, a task achieved via the activity of NKA. Therefore, there should exist cross-talk between AMPARs and the NKA to coordinate their functions. Indeed, we have shown that sodium pumps are enriched at the synapse and physically associate with AMPARs via interactions between the pump and receptor intracellular C-terminals. AMPAR surface localization and thus activity intensity are controlled to match the functional capacity of the pump. When sodium pump activity is decreased, AMPARs undergo a translocation from the plasma membrane to intracellular compartments via endocytosis, which are then directed to the proteasome for degradation. Presumably, the adjustment in surface glutamate receptor number can help prevent drastic toxicity caused by sodium and calcium accumulation due to sodium pump insufficiency. It remains unclear whether and how changes in glutamate receptor activity lead to corresponding regulation of NKA. However, changes in sodium pump levels correlating with glutamate receptor density have been documented. In the macaque retina, TTX treatment for 4 weeks caused a significant reduction in NMDARs; this reduction was paralleled by a lower level of NKA, suggesting that glutamate activity regulates NKA levels (38).

\section{SYNAPTIC ACTIVATION REGULATES GLUCOSE UPTAKE}

Glucose is the sole source for ATP production in neurons (1). Therefore, it is of physiological significance to have synaptic activity coupled with glucose uptake. Both neurons and glia are 
equipped with glucose utilization machinery, including glucose transporters and regulators, however higher glucose demands seem to be fulfilled with the assistance from glia. Glucose is first taken up by glia to be converted into lactate via glycolysis, which is then released and retaken by neurons where lactate is used for oxidative ATP genesis in mitochondria. Processes of astrocytes grow in the close proximity to neurons, often wrapping the synaptic cleft, as evidenced by a concentration of the astrocytic glucose transporter GLUT1 around synapses, where glutamate released during synaptic transmission is sensed by the glia and stimulate glial glucose uptake $(39,40)$.

In addition to the glia-coupled glucose delivery to neurons, synaptic activity can directly stimulate neuronal glucose uptake (41). However, exposure of neurons to glutamate results in a reduction in cellular ATP levels (20) and glucose uptake in neurons (42), indicating distinct signaling and cellular responses to synaptic vs. non-synaptic glutamate receptor activation.

AMPK is implicated in glutamate-induced glucose uptake. In neurons, AMPK signaling leads to activation of the PI3K/Akt pathway. We have shown that in cultured hippocampal neurons application of the AMPK activator AICAR causes a marked increase in phosphorylated Akt (43). This effect results directly from AMPK activation, as introduction of the AMPK antagonist successfully blocks AICAR-induced Akt phosphorylation. Furthermore, addition of a PI3K inhibitor also abolishes AICAR-induced Akt phosphorylation, indicating that the AMPK effect on Akt activation is mediated via PI3K (43) Interestingly, glutamate treatment activates AMPK, and pharmacological activation of AMPK leads to increased amounts of glucose transporters at the cell surface (44). We have recently found that in hippocampal neurons, AMPK activation causes higher levels of membrane GLUT3 and enhances glucose uptake (unpublished data). How AMPK activates PI3K remains unclear. Upon AICAR treatment, AMPK activation has been shown to phosphorylate IRS-1, the upstream component in the PI3K signaling pathway (45), suggesting IRS-1 as the intermediate factor linking AMPK to PI3K/Akt activation. Considering that glutamate-induced ATP reduction is a typical condition for AMPK activation $(20,46)$, the AMPK-PI3K-mediated enhancement in glucose uptake may function to prevent energy depletion and neuronal excitotoxicity. In addition, phosphorylated Akt may have a stimulatory effect on respiration by translocating to the mitochondria and increasing ATP synthase activity (47).

\section{GLUTAMATE TRANSPORTER AND GLUTAMATE RECEPTOR ACTIVITY IN NEURONAL ENERGY CONSUMPTION}

Glutamate is an extremely ample neurotransmitter, ranging to levels of 5-10 mmol/kg of brain tissue (48) and reaching millimolar concentrations within the synaptic cleft during synaptic transmission (49). However, glutamate levels are maintained in the microto nano-molar concentration in the extracellular milieu (50), many fold against its concentration gradient (12, 51-53). Unlike some neurotransmitters such as acetylcholine, which are efficiently removed by enzymatic digestion at the synaptic cleft, such disposal mechanism for glutamate does not exist. Instead, following release, glutamate is rapidly taken up by glia and neurons via membranedistributed glutamate transporters $(12,54)$. By rapidly binding and transporting glutamate from the synaptic cleft, transporters limit the amount of glutamate receptor-permitted calcium influx and the subsequent excitotoxicity, a principal process involved in neuronal damage and neurodegeneration (55-57).

To date, five excitatory amino acid transports (EAAT1-5) have been identified in glia and neurons. The glial transporters EAAT12 are primarily localized to the plasma membrane of specialized domains in astrocytic processes $(58,59)$. The distribution of the neuronal transporters shows cell type specificity. EAAT3 is expressed in most neurons, including hippocampal and cortical neurons, whereas EAAT4 is mainly localized in cerebellar Purkinje cells and EAAT5 is restricted to the ribbon synapses of rod bipolar cells in the retina $(60,61)$. The majority of glutamate re-uptake is conducted by the glial transporters EAAT1 and EAAT2 $(62,63)$ which are expressed abundantly at the glial plasma membrane (59, 64) located in close proximity to synaptic release sites (65).

Glutamate transport by EAATs is powered indirectly by the sodium gradient across the membrane. During one complete cycle of glutamate transport, an EAAT brings one glutamate molecule against its concentration gradient, together with three $\mathrm{Na}^{+}$ions and one $\mathrm{H}^{+}$ion into the cell, meanwhile counter-transporting one $\mathrm{K}^{+}$ion out of the cell, thereby resetting the transporter to the outward-facing conformation $(66,67)$. During stroke and brain trauma, a large amount of glutamate release is coupled with elevated activity of EAATs attempting to restore extracellular glutamate concentration. Despite EAAT activity being an ultimately energy consuming event, glutamate removal prevents overexcitation of glutamate receptors including AMPARs and NMDARs, which are ion channels with higher energy cost, and thus reduces net energy consumption. Indeed, inhibition of EAATs results in a decrease in ATP amount, which can be completely blocked by the glutamate receptor antagonists, indicating that local glutamate stimulation at synaptic sites causes ATP reductions similar to that caused by global glutamate application (20). Interestingly, glutamate uptake is powered mainly by glycolytic metabolism both in glia and neurons (68).

An additional layer of co-ordination exists between synaptic activity and glutamate receptor trafficking. In response to glutamate release and binding, glutamate receptors, especially the primary synaptic mediator AMPARs, undergo rapid translocation from the plasma membrane to the cytosolic domain via receptor internalization $(69,70)$. Elevated neuronal network activity or synaptic glutamate accumulation as a result of transporter suppression lead to AMPAR internalization (71). AMPAR trafficking has been extensively studied as a mechanism for synaptic plasticity and learning, but it may also play a role in energy homeostasis, especially in neurotraumatic conditions to prevent receptor overexcitation and rapid depletion of cellular energy store.

\section{SYNAPTIC ACTIVITY AND MITOCHONDRIA FUNCTION AND TRANSLOCATION}

Mitochondria are responsible for generating and providing energy in the form of ATP in eukaryotic cells. In addition to converting glucose into ATP, mitochondria are involved in calcium signaling, apoptosis, and the metabolism of reactive oxygen species (ROS). With such high energy demands, neurons rely heavily on the proper functioning of mitochondria. The 
significance of this organelle in neurons has been shown by the implication of mitochondrial dysfunction in several neurodegenerative diseases (72). Mitochondria are also involved in other neurobiological processes including neural differentiation, neurite outgrowth, neurotransmitter release, and dendritic remodeling (73).

Because regions of highest energy consumption in the neuron are located at the synapses, mitochondrial transport and distribution are critical, since diffusion of ATP from the center of the neuron would be too slow and inefficient (74). Mitochondrial movement in dendrites is increased in areas with high levels of ATP and decreased in areas containing higher levels of ADP, suggesting that low levels of ATP signal the mitochondria to remain in the area so as to increase local energy supply (75). Dendrites contain a greater proportion of highly charged, more metabolically active mitochondria than axons to match energy demands of local activity. In accordance, axonal mitochondria are more mobile compared to those in the dendrites (76). This activitydependent mitochondrial stopping results from NMDAR-gated calcium rises, which lead to a recruitment of mitochondria to the synapse (77). Mitochondria use the dynein and kinesin motor complexes to move in the retrograde and anterograde directions, respectively. Specifically, the core of this motor/adaptor complex is made up of kinesin-1, the protein Miro that is anchored to the outer surface of the mitochondria, and Milton, which links kinesin and Miro. A fine balance and regulation of the movements based on these complexes determine where mitochondria will be static or motile to provide adequate ATP for neuronal activity. Elevation of cytosolic $\mathrm{Ca}^{2+}$, which arises from activation of glutamate receptors in dendrites, stops both the anterograde and retrograde movement of mitochondria in neurons (77), which may be regulated by a $\mathrm{Ca}^{2+}$ binding site on Miro (78). How this regulation occurs remains unclear, although proposed mechanisms have included a conformational change in the complex triggered by $\mathrm{Ca}^{2+}$ (77), and direct binding of $\mathrm{Ca}^{2+}$ to kinesin, thereby preventing Miro from interacting with microtubules to allow mitochondrial movement (79).

Although less than synapses, axons themselves are also energydemanding sites, as they are responsible for generating and conducting action potentials along the length of the neuron. In the peripheral nervous system, the nodes of Ranvier harbor the highest density of $\mathrm{Na}^{+}$channels to sustain saltatory conduction (80). During action potentials, mitochondria are recruited to the nodal region and their mobility is reduced to provide more ATP (81). In addition, mitochondria motility seems to be crucial for axon growth and branching. A recent study shows that LKB1NUAK1 signaling immobilize mitochondria in the axon where locally produced energy presumably supports formation of axon branches (82).

The regulation of mitochondrial function occurs both presynaptically and postsynaptically in the brain. In the presynaptic zone, the cycle of SVs in neuronal synapses involves steps regulated by cytosolic calcium concentrations and dependent on mitochondrial function. Upon the arrival of an action potential at the nerve terminal, voltage-gated $\mathrm{Ca}^{2+}$ channels open and allow an influx of calcium into the terminals. The elevated cytosolic calcium negatively affects mitochondria transport along microtubules, causing them to pause, and accumulate close to the active zones where SVs will fuse to the membrane (83). Synapses tend to have an accumulation of mitochondria that have high electrical potential across their inner membranes and are capable of enhanced ATP production (84).

Regulation of mitochondrial function in the postsynaptic region of the dendrite involves responses to glutamate to increase glucose uptake and ATP production. Synaptic activity increases surface expression of GLUT3 leading to an elevation of intracellular glucose (85). This effect is NMDAR-dependent and involves nNOS phosphorylated by Akt. As glutamate itself is utilized by mitochondria to produce ATP, the transport of glutamate into mitochondria is also regulated by activity. Interestingly, EAAT3 (EAAC1) has been shown to be expressed in neuronal and glial mitochondria where it participates in glutamate-stimulated ATP production (86).

\section{ENERGY DYSREGULATION IN ISCHEMIA AND STROKE}

Under normal conditions, high glutamate concentrations only occur at the synaptic cleft; ambient glutamate concentrations are maintained at very low levels (50). However, during traumatic brain injury (TBI) or stroke, massive glutamate release can lead to a marked increase in extracellular glutamate and hyperactivity of the overall glutamate system, causing additional acute and delayed neural pathology. Energy depletion plays a key role in glutamate-induced neurotoxicity (87-90). Glutamate stimulation causes more severe cell death when cellular energy homeostasis is impaired (88). A lack of sufficient ATP undermines a large number of energy-dependent cellular processes including kinase/enzymatic activity, proteasomal protein turnover, transmembrane biochemical gradients, and membrane potentials, all leading to a collapse of cellular functional integrity and deterioration of cell conditions. As the primary energy user consuming half of the ATP in the brain, sodium pump activity is highly sensitive to ATP levels. Under energy deficient conditions such as hypoxia, ischemia, and stroke, NKA dysfunction is often a major early pathological response $(91,92)$, which leads to a loss in membrane potential and neuronal function.

Ischemic stroke-induced energy depletion is sensed by the master metabolic regulator AMPK. AMPK activation has been observed in glutamate-treated neurons and a variety of ischemia/stroke models both in vitro (93) and in vivo (94). Because AMPK activation results in enhanced catalytic and suppressed anabolic metabolism, AMPK activity helps to relieve energy stress and is beneficial for neuronal conditions. Studies have shown that in cultured neurons AMPK activation reduces neuronal cell death caused by ischemia/hypoxia (93), whereas AMPK inhibition during energy stress stimulation leads to more severe damage (95). However, there are also studies showing deleterious effects of AMPK. In vivo ischemia model shows that blockade of AMPK by Compound C suppressed neural injury (96). Consistently, knockout of AMPK $\alpha 2$ results in a reduction of brain damage (97). Mechanisms for the detrimental effects of AMPK are not clear. Possibly, when cells are under conditions of metabolic stress, forced energy production pushes the metabolic machinery over its limits, causing a collapse of the system and irreversible structural and functional failure. 


\section{ALTERATIONS OF BIOENERGY METABOLISM IN NEURODEGENERATIVE DISEASES}

Given that the brain is the major energy consumer in the body, and neurons rely heavily on ATP production for development and function, even a slight impairment in energy metabolism can have drastic effects on the brain. In line with this, mitochondria and bioenergy defects have long been proposed as the mechanism underlying chronic neuronal dysfunction and death, and an increasing amount of evidence has been accumulated in support of the hypothesis (Figure 1).

Alzheimer's Disease (AD) is a neurodegenerative disease characterized by progressive memory loss and cognitive deficits. Its pathological hallmarks are neuronal loss, extracellular plaques consisting of $\mathrm{A} \beta$ aggregates and intracellular neurofibrillary tangles made up of hyperphosphorylated tau. Although the exact cause of neuronal death has not yet been determined, many studies suggest that dysfunction of energy metabolism may be responsible for neuronal deficits contributing to cell death. Indeed, AD patients exhibit reduced glucose energy metabolism, even at an early stage of disease. Positron emission tomography (PET) imaging with the $2-[18 \mathrm{~F}]$-fluorodeoxyglucose (FDG) tracer has long been used to track AD-related changes in the brain by estimating the cerebral metabolic rate of glucose (CMRglc). FDG-PET studies in AD show consistent and progressive CMRglc reductions. Compared to agematched healthy controls, $\mathrm{AD}$ patients show metabolic reductions in the parieto-temporal and posterior cingulated cortices in early and late-onset $\operatorname{AD}(98,99)$, and in the frontal areas in advanced disease (99-102). These changes in glucose metabolism could be caused by a reduction of glucose uptake through glucose transporters, mitochondrial dysfunction, or changes in mitochondrial movement.

The neuronal glucose transporter GLUT3 level is reduced in the AD brain (103). Full-length cAMP response element binding protein (CREB), which is reduced in AD brain along with an increase in the truncated form, regulates the expression of GLUT3. Calpain I proteolyses CREB at Gln28-Ala29 to generate a 41-kDa truncated CREB, which is less active in promoting GLUT3 expression, supported by the observation that activation of calpain I itself also reduces GLUT3 expression. It has been suggested that overactivation of calpain I by calcium overload proteolyses CREB, resulting in a reduction of GLUT3 expression, and consequently impairing glucose uptake and metabolism in AD brain (104). AMPK, as a sensor and regulator of cellular energy metabolism, has been shown to decrease with aging, and may contribute to decreased mitochondrial function in AD (105). A study using quercetin, a natural flavonoid and activator of AMPK, showed that activation of AMPK reduces oxidative stress, improves mitochondrial dysfunction and impaired glucose uptake in $\mathrm{AD}$, and slows down $\mathrm{A} \beta$ accumulation (106).

Characterization of mitochondrial dynamics and function in three mouse models of familial AD (FAD) (APP, PS1, and $\mathrm{APP} / \mathrm{PS} 1$ ) revealed mitochondrial dysfunction before the onset of memory phenotype and the formation of amyloid plaques (107). Movement of mitochondria in both anterograde and retrograde directions in FAD neurons was significantly inhibited compared to wild-type neurons. This reduced motility correlated with increased excitotoxic neuronal cell death by NMDA in all three
FAD mouse models, consistent with the essential role for mitochondrial motility and positioning in proper calcium buffering (83). Additionally, similar effects were seen in mouse hippocampal neurons treated with the $A \beta(23-35)$ peptide. Compared to the control neurons, which showed approximately $35 \%$ mobile mitochondria, motile mitochondria in the $A \beta$-treated neurons were significantly reduced to $20 \%$, suggesting that the $A \beta(25-35)$ peptide impairs axonal transport of mitochondria in $\mathrm{AD}$ neurons. This reduction in mitochondrial dynamics also correlated with, and was suggested to be causing, a reduction in synaptic proteins synaptophysin and MAP2. In the Tg2576 AD mouse model, where a significant decrease in mitochondrial movement was also seen (108), the mitochondria-targeted antioxidant SS31, which reduces intracellular free radicals (109), restored mitochondrial transport and synaptic viability, and decreased the percentage of defective mitochondria, implicating the important role of mitochondrial function in the disease. A recent report, however, found no consistent presynaptic bioenergetic deficiencies in three mouse models of AD pathogenesis (J20, Tg2576, and APP/PS1) (110). APP/PS1 cortical synaptosomes showed an increase in respiration associated with proton leak, but calcium handling and membrane potentials of synaptosomes were not consistently impaired. The disparities between these studies may be due to the mouse models used and the age of the animal when mitochondrial dysfunction was examined. In transgenic Drosophila expressing human tau, RNAi-mediated knockdown of Milton or Miro enhanced tauinduced neurodegeneration and increased tau phosphorylation at the AD-related site Ser262. Correlated with pathological conditions implicated in $\mathrm{AD}$, a reduction in the number of axonal mitochondria was also observed, and knockdown of Miro alone was sufficient to induce late-onset neurodegeneration in the fly brain (111).

Parkinson's disease (PD) is characterized pathologically by the selective degeneration of dopaminergic neurons in the substantia nigra pas compacta and the presence of Lewy bodies, intraneuronal aggregates comprised primarily of alpha-synuclein ( $\alpha$-syn). A mutation in $\alpha$-syn, A53T, has been identified to cause familial Parkinson's disease (112), and $\alpha$-syn transgenic PD models display impaired mitochondrial function and decreased mitochondrial movement $(113,114)$. In addition, mutations in other Parkinson related proteins, such as PINK1, parkin, and DJ-1, are also believed to be involved in the regulation of mitochondrial function (115-117).

Huntington's disease (HD) is an autosomal dominant neurodegenerative disease characterized by motor and cognitive impairment and caused by a trinucleotide repeat expansion encoding an elongated glutamine tract in the Huntingtin (htt) protein (118). Reduced energy metabolism has been well documented in HD patients. PET scan analysis of HD patients revealed diminished rates of cerebral glucose metabolism in parts of the cortex and throughout the striatum (119). Additionally, HD patient material was found to have significant reductions in the enzymatic activities of complexes II, III, and IV of the mitochondrial oxidative phosphorylation pathway in caudate and putamen $(120,121)$. BACHD mice of mutant Htt were found to have abnormal mitochondrial dynamics, supposedly due to the interaction of mutant Htt with the mitochondrial protein Drp1, resulting in defective anterograde 
movement (122). A major player implicated in mitochondrial dysfunction in Huntington's, as well as Parkinson's, is PPAR $\gamma$ coactivator-1 $\alpha$ (PGC-1 $\alpha)$. As a transcription co-activator, PGC- $1 \alpha$ regulates the expression of various genes to promote mitochondrial biogenesis and oxidative phosphorylation. Impaired PGC- $1 \alpha$ function is a likely contributor to HD pathology, as demonstrated by reduced PGC- $1 \alpha$ target gene expression in HD transgenic mice (123). PGC-1 $\alpha$ transcriptional activity is also repressed in a conditional knockout model of parkin (124), and activation of PGC- $1 \alpha$ could rescue dopaminergic neuron loss induced by mutant $\alpha$-syn (125). Consistently, PGC-1 $\alpha$ has been suggested as a promising therapeutic target for $\mathrm{HD}$ and $\mathrm{PD}$, either by boosting PGC$1 \alpha$ expression by viral delivery, or by modulating the upstream activators of PGC-1 $\alpha$ activity, such as SIRT1 and AMPK (126).

\section{IMPLICATIONS OF ENERGY HOMEOSTASIS IN TRAUMATIC BRAIN INJURY}

Traumatic brain injury (TBI) is a complex brain damage by an external force that causes brain penetrating or closed-head injuries. Recently, TBI has become an increasing concern in the population, as almost 179,000 service members sustained a TBI during the Iraq and Afghanistan wars (127). Additionally, repeated injury to the brain, especially concussions, can lead to CTE, a neurodegenerative disease that has been discovered in brain tissues of athletes who have sustained many close head and concussions injuries over time $(128,129)$. The complex mechanism by which TBI triggers pathological processes and long-term neurobehavioral abnormalities are still not well understood. Mechanistic investigation is critical to guide the identification of compounds to prevent acute neuronal damage and subsequent effects.

Traumatic brain injuries cause a vast array of primary structural damages that lead to secondary effects including cellular, inflammatory, neurochemical, and metabolic alterations. In the early phases after injury, changes such as metabolic impairment, reductions in cerebral blood flow, low ATP and energy stores, severe ionic shifts, and alterations in the permeability of the blood-brain barrier are seen. Thereafter, brain lactate production increases for the first few days, indicating a shift from aerobic to anaerobic metabolism to maintain ATP production, while glucose levels decline rapidly, as measured by microdialysis in affected patients (130). High levels of lactate in the brain during this period of ischemia may cause additional harmful effects; cerebral acidosis may exacerbate calcium-mediated damage to intracellular pathways and may interfere with ion-channel function (131). ATP levels are decreased following a TBI, along with reduced availability of the nicotinic coenzyme pool, which declines proportionally with the gravity of brain insult (132). The degree of oxidative metabolism depression also correlates with the depth of coma after severe TBI, as indicated by the Glasgow Coma Scale (GSC) (133). In mice, a single blast resulted in a $20 \%$ decrease in ATP levels in the cerebral cortex at $6 \mathrm{~h}$ after the blast, whereas triple blasts resulted in a similar decrease as early as $1 \mathrm{~h}$ (134). A significant, though less severe, decrease remained $24 \mathrm{~h}$ after the blast. Energy failure leads to degradation of molecules of key importance to membrane and cytoskeletal integrity. It also causes a disruption in ion homeostasis, especially calcium rises, and an increase in cytosolic acidity. The rise in free cytosolic $\mathrm{Ca}^{2+}$ is a result of failed calcium pump function, increased membrane permeability to calcium, and decreased sequestration of intracellular calcium. Elevated calcium levels and oxidative stress lead to the opening of the mitochondrial permeability transition pore $(\mathrm{mPTP})$, which depolarizes the mitochondrial membrane and leads to organelle swelling and subsequent release of cytochrome $c$, leading to caspase-dependent cell death $(135,136)$. Specific inhibitors of the mPTP are currently under investigation as treatment immediately after TBI to prevent neuronal damage (137).

Mitochondrial dysfunction in TBI may be caused by several mechanisms in addition to the opening of mPTP. Nitric oxide (NO) is believed to cause respiratory chain inhibition in mitochondria after TBI (138), as it has the ability to interfere with energy metabolism by inhibiting the enzymatic activity of complex IV of the electron transport chain. An increase in NO production has been observed in closed-head trauma animal models (139), caused by the increase in the production of inducible NO synthase (iNOS) (140), as indicated by the rapid upregulation of iNOS mRNA at $4 \mathrm{~h}$ after injury. The inhibition of pyruvate dehydrogenase $(\mathrm{PDH})$ has also been implicated in causing mitochondrial damage in TBI. PDH is tightly regulated by end-product inhibition and reversible phosphorylation, and a significant decrease in both PDH enzyme levels (141) and PDH phosphorylation (142) was found in rat TBI models. In addition, activation of poly(adenosine diphosphate [ADP]-ribose) polymerase-1 (PARP1) could be responsible for impaired mitochondrial respiration. PARP-1 senses DNA damage after injury and becomes overactivated, depletes $\mathrm{NAD}^{+} / \mathrm{NADH}$ stores, and impairs the utilization of oxygen for ATP synthesis (143). In support of this mechanism, administration of $\mathrm{NAD}^{-}$or the PARP inhibitor GP 6150 was found to be neuroprotective after TBI in rats $(144,145)$. Similar blockade of mitochondrial damage and metabolic disturbances in the early events occurring immediately after an injury are currently under investigation, which will be advanced following a better understanding of the molecular mechanisms underlying primary TBI impacts.

\section{CONCLUSION}

Excitatory glutamatergic synaptic transmission is the major energy-consuming cellular process in the brain. Therefore, it is critical for neurons to couple synaptic activities with energetic metabolism, and to have adaptive mechanisms in response to metabolic stress and neuronal overexcitation. Dysfunctions in the regulatory system and bioenergy homeostasis can lead to defects in neural development and brain function, and contribute to the pathogenesis of neurodegenerative diseases and traumatic brain injuries. It will be important to further our understandings of how synaptic activity communicates with the metabolic and energetic machineries, including energy sensing, energetic signaling, bioenergy metabolism, and mitochondria dynamics. Age-dependent changes in bioenergy homeostasis, and epigenetic control of the energetic processes are also in need of further investigation.

\section{ACKNOWLEDGMENTS}

We thank Man Lab members for helpful comments on the manuscript. This work was supported by NIH grant MH079407 (Heng-Ye Man). 


\section{REFERENCES}

1. Attwell D, Laughlin SB. An energy budget for signaling in the grey matter of the brain. J Cereb Blood Flow Metab (2001) 21:1133-45. doi:10.1097/00004647200110000-00001

2. Magistretti PJ, Pellerin L. Metabolic coupling during activation. A cellular view. Adv Exp Med Biol (1997) 413:161-6. doi:10.1007/978-1-4899-0056-2_18

3. Magistretti PJ, Pellerin L, Rothman DL, Shulman RG. Energy on demand. Science (1999) 283:496-7. doi:10.1126/science.283.5401.496

4. Raichle ME, Gusnard DA. Appraising the brain's energy budget. Proc Natl Acad Sci U S A (2002) 99:10237-9. doi:10.1073/pnas.172399499

5. Rao J, Oz G, Seaquist ER. Regulation of cerebral glucose metabolism. Minerva Endocrinol (2006) 31:149-58.

6. Elia M. Organ and tissue contribution to metabolic rate. In: Kinney JM, Tucker HN, editors. Energ Metabolism: Tissue Determinants and Cellular Corollaries. New York, NY: Raven Press (1992). p. 61-80.

7. Alle H, Roth A, Geiger JR. Energy-efficient action potentials in hippocampal mossy fibers. Science (2009) 325:1405-8. doi:10.1126/science.1174331

8. Howarth C, Gleeson P, Attwell D. Updated energy budgets for neural computation in the neocortex and cerebellum. J Cereb Blood Flow Metab (2012) 32:1222-32. doi:10.1038/jcbfm.2012.35

9. Jolivet R, Magistretti PJ, Weber B. Deciphering neuron-glia compartmentalization in cortical energy metabolism. Front Neuroenergetics (2009) 1:4. doi:10.3389/neuro.14.004.2009

10. Shen J, Petersen KF, Behar KL, Brown P, Nixon TW, Mason GF, et al. Determination of the rate of the glutamate/glutamine cycle in the human brain by in vivo 13C NMR. Proc Natl Acad Sci U S A (1999) 96:8235-40. doi:10.1073/pnas.96.14.8235

11. Sibson NR, Dhankhar A, Mason GF, Rothman DL, Behar KL, Shulman RG. Stoichiometric coupling of brain glucose metabolism and glutamatergic neuronal activity. Proc Natl Acad Sci U S A (1998) 95:316-21. doi:10.1073/pnas.95. 1.316

12. Danbolt NC. Glutamate uptake. Prog Neurobiol (2001) 65:1-105. doi:10.1016/ S0301-0082(00)00067-8

13. Tzingounis AV, Wadiche JI. Glutamate transporters: confining runaway excitation by shaping synaptic transmission. Nat Rev Neurosci (2007) 8:935-47. doi:10.1038/nrn2274

14. Collingridge GL, Isaac JT, Wang YT. Receptor trafficking and synaptic plasticity. Nat Rev Neurosci (2004) 5:952-62. doi:10.1038/nrn1556

15. Man HY, Ju W, Ahmadian G, Wang YT. Intracellular trafficking of AMPA receptors in synaptic plasticity. Cell Mol Life Sci (2000) 57:1526-34. doi:10.1007/ PL00000637

16. Newpher TM, Ehlers MD. Glutamate receptor dynamics in dendritic microdomains. Neuron (2008) 58:472-97. doi:10.1016/j.neuron.2008.04.030

17. Kim MJ, Dunah AW, Wang YT, Sheng M. Differential roles of NR2A- and NR2B-containing NMDA receptors in Ras-ERK signaling and AMPA receptor trafficking. Neuron (2005) 46:745-60. doi:10.1016/j.neuron.2005.04.031

18. Skeberdis VA, Chevaleyre V, Lau CG, Goldberg JH, Pettit DL, Suadicani SO, et al. Protein kinase A regulates calcium permeability of NMDA receptors. Nat Neurosci (2006) 9:501-10. doi:10.1038/nn1664

19. Rose CR, Konnerth A. NMDA receptor-mediated Na+ signals in spines and dendrites. J Neurosci (2001) 21:4207-14.

20. Foo K, Blumenthal L, Man HY. Regulation of neuronal bioenergy homeostasis by glutamate. Neurochem Int (2012) 61:389-96. doi:10.1016/j.neuint.2012.06. 003

21. Bateman A. The structure of a domain common to archaebacteria and the homocystinuria disease protein. Trends Biochem Sci (1997) 22:12-3. doi:10.1016/S0968-0004(96)30046-7

22. Scott JW, Hawley SA, Green KA, Anis M, Stewart G, Scullion GA, et al. CBS domains form energy-sensing modules whose binding of adenosine ligands is disrupted by disease mutations. J Clin Invest (2004) 113:274-84. doi:10.1172/JCI19874

23. Xiao B, Heath R, Saiu P, Leiper FC, Leone P, Jing C, et al. Structural basis for AMP binding to mammalian AMP-activated protein kinase. Nature (2007) 449:496-500. doi:10.1038/nature06161

24. Hawley SA, Davison M, Woods A, Davies SP, Beri RK, Carling D, et al. Characterization of the AMP-activated protein kinase kinase from rat liver and identification of threonine 172 as the major site at which it phosphorylates AMP-activated protein kinase. J Biol Chem (1996) 271:27879-87. doi:10.1074/jbc.271.44.27879
25. Baron SJ, Li J, Russell RR III, Neumann D, Miller EJ, Tuerk R, et al. Dual mechanisms regulating AMPK kinase action in the ischemic heart. Circ Res (2005) 96:337-45. doi:10.1161/01.RES.0000155723.53868.d2

26. Clark SA, Chen ZP, Murphy KT, Aughey RJ, McKenna MJ, Kemp BE, et al. Intensified exercise training does not alter AMPK signaling in human skeletal muscle. Am J Physiol Endocrinol Metab (2004) 286:E737-43. doi:10.1152/ ajpendo.00462.2003

27. Woods A, Dickerson K, Heath R, Hong SP, Momcilovic M, Johnstone SR, et al. $\mathrm{Ca} 2+/$ calmodulin-dependent protein kinase kinase-beta acts upstream of AMP-activated protein kinase in mammalian cells. Cell Metab (2005) 2:21-33. doi:10.1016/j.cmet.2005.06.005

28. Woods A, Vertommen D, Neumann D, Turk R, Bayliss J, Schlattner U, et al. Identification of phosphorylation sites in AMP-activated protein kinase (AMPK) for upstream AMPK kinases and study of their roles by site-directed mutagenesis. J Biol Chem (2003) 278:28434-42. doi:10.1074/jbc.M303946200

29. Avizienyte E, Roth S, Loukola A, Hemminki A, Lothe RA, Stenwig AE, et al. Somatic mutations in LKB1 are rare in sporadic colorectal and testicular tumors. Cancer Res (1998) 58:2087-90.

30. Hawley SA, Boudeau J, Reid JL, Mustard KJ, Udd L, Makela TP, et al. Complexes between the LKB1 tumor suppressor, STRAD alpha/beta and MO25 alpha/beta are upstream kinases in the AMP-activated protein kinase cascade. J Biol (2003) 2:28. doi:10.1186/1475-4924-2-28

31. Shaw RJ, Kosmatka M, Bardeesy N, Hurley RL, Witters LA, DePinho RA, et al. The tumor suppressor LKB1 kinase directly activates AMP-activated kinase and regulates apoptosis in response to energy stress. Proc Natl Acad Sci U S A (2004) 101:3329-35. doi:10.1073/pnas.0308061100

32. Sakamoto K, McCarthy A, Smith D, Green KA, Grahame Hardie D, Ashworth A, et al. Deficiency of LKB1 in skeletal muscle prevents AMPK activation and glucose uptake during contraction. EMBO J (2005) 24:1810-20. doi:10.1038/sj.emboj.7600667

33. Shaw RJ, Lamia KA, Vasquez D, Koo SH, Bardeesy N, Depinho RA, et al. The kinase LKB1 mediates glucose homeostasis in liver and therapeutic effects of metformin. Science (2005) 310:1642-6. doi:10.1126/science.1120781

34. Barnes AP, Lilley BN, Pan YA, Plummer LJ, Powell AW, Raines AN, et al. LKB1 and SAD kinases define a pathway required for the polarization of cortical neurons. Cell (2007) 129:549-63. doi:10.1016/j.cell.2007.03.025

35. Hawley SA, Pan DA, Mustard KJ, Ross L, Bain J, Edelman AM, et al. Calmodulin-dependent protein kinase kinase-beta is an alternative upstream kinase for AMP-activated protein kinase. Cell Metab (2005) 2:9-19. doi:10. 1016/j.cmet.2005.05.009

36. Anupama Adya HV, Mallick BN. Comparison of Na-K ATPase activity in rat brain synaptosome under various conditions. Neurochem Int (1998) 33:283-6. doi:10.1016/S0197-0186(98)00043-6

37. Brines ML, Robbins RJ. Cell-type specific expression of $\mathrm{Na}+, \mathrm{K}(+)$-ATPase catalytic subunits in cultured neurons and glia: evidence for polarized distribution in neurons. Brain Res (1993) 631:1-11. doi:10.1016/0006-8993(93)91179-V

38. Wong-Riley MT, Huang Z, Liebl W, Nie F, Xu H, Zhang C. Neurochemical organization of the macaque retina: effect of TTX on levels and gene expression of cytochrome oxidase and nitric oxide synthase and on the immunoreactivity of $\mathrm{Na}+\mathrm{K}+$ ATPase and NMDA receptor subunit I. Vision Res (1998) 38:1455-77. doi:10.1016/S0042-6989(98)00001-7

39. Loaiza A, Porras OH, Barros LF. Glutamate triggers rapid glucose transport stimulation in astrocytes as evidenced by real-time confocal microscopy. J Neurosci (2003) 23:7337-42.

40. Morgello S, Uson RR, Schwartz EJ, Haber RS. The human blood-brain barrier glucose transporter (GLUT1) is a glucose transporter of gray matter astrocytes. Glia (1995) 14:43-54. doi:10.1002/glia.440140107

41. Bak LK, Walls AB, Schousboe A, Ring A, Sonnewald U, Waagepetersen HS. Neuronal glucose but not lactate utilization is positively correlated with NMDAinduced neurotransmission and fluctuations in cytosolic Ca2+ levels. J Neurochem (2009) 109(Suppl 1):87-93. doi:10.1111/j.1471-4159.2009.05943.x

42. Porras $\mathrm{OH}$, Loaiza A, Barros LF. Glutamate mediates acute glucose transport inhibition in hippocampal neurons. J Neurosci (2004) 24:9669-73. doi:10.1523/JNEUROSCI.1882-04.2004

43. Amato S, Liu X, Zheng B, Cantley L, Rakic P, Man HY. AMP-activated protein kinase regulates neuronal polarization by interfering with PI 3-kinase localization. Science (2011) 332:247-51. doi:10.1126/science.1201678

44. Weisova P, Concannon CG, Devocelle M, Prehn JH, Ward MW. Regulation of glucose transporter 3 surface expression by the AMP-activated protein 
kinase mediates tolerance to glutamate excitation in neurons. J Neurosci (2009) 29:2997-3008. doi:10.1523/JNEUROSCI.0354-09.2009

45. Jakobsen SN, Hardie DG, Morrice N, Tornqvist HE. 5'-AMP-activated protein kinase phosphorylates IRS-1 on Ser-789 in mouse C2C12 myotubes in response to 5-aminoimidazole-4-carboxamide riboside. J Biol Chem (2001) 276:46912-6. doi:10.1074/jbc.C100483200

46. Ioudina M, Uemura E, Greenlee HW. Glucose insufficiency alters neuronal viability and increases susceptibility to glutamate toxicity. Brain Res (2004) 1004:188-92. doi:10.1016/j.brainres.2003.12.046

47. Li C, Li Y, He L, Agarwal AR, Zeng N, Cadenas E, et al. PI3K/AKT signaling regulates bioenergetics in immortalized hepatocytes. Free Radic Biol Med (2013) 60:29-40. doi:10.1016/j.freeradbiomed.2013.01.013

48. Butcher SP, Hamberger A. In vivo studies on the extracellular, and veratrinereleasable, pools of endogenous amino acids in the rat striatum: effects of corticostriatal deafferentation and kainic acid lesion. J Neurochem (1987) 48:713-21. doi:10.1111/j.1471-4159.1987.tb05575.x

49. Clements JD, Lester RA, Tong G, Jahr CE, Westbrook GL. The time course of glutamate in the synaptic cleft. Science (1992) 258:1498-501. doi:10.1126/ science. 1359647

50. Herman MA, Jahr CE. Extracellular glutamate concentration in hippocampal slice. J Neurosci (2007) 27:9736-41. doi:10.1523/JNEUROSCI.3009-07.2007

51. Kanner BI, Schuldiner S. Mechanism of transport and storage of neurotransmitters. CRC Crit Rev Biochem (1987) 22:1-38. doi:10.3109/ 10409238709082546

52. Kanner BI, Sharon I. Active transport of L-glutamate by membrane vesicles isolated from rat brain. Biochemistry (1978) 17:3949-53. doi:10.1021/ bi00600a011

53. Stern JR, Eggleston LV. Accumulation of glutamic acid in isolated brain tissue. Biochem J (1949) 44:410-8.

54. Schousboe A. Transport and metabolism of glutamate and GABA in neurons are glial cells. Int Rev Neurobiol (1981) 22:1-45. doi:10.1016/S0074-7742(08) 60289-5

55. Arundine M, Tymianski M. Molecular mechanisms of calcium-dependent neurodegeneration in excitotoxicity. Cell Calcium (2003) 34:325-37. doi:10.1016/ S0143-4160(03)00141-6

56. Choi DW. Excitotoxic cell death. J Neurobiol (1992) 23:1261-76. doi:10.1002/ neu. 480230915

57. Man HY. GluA2-lacking, calcium-permeable AMPA receptors - inducers of plasticity? Curr Opin Neurobiol (2011) 21:291-8. doi:10.1016/j.conb.2011.01. 001

58. Chaudhry FA, Lehre KP, van Lookeren Campagne M, Ottersen OP, Danbolt NC, Storm-Mathisen J. Glutamate transporters in glial plasma membranes: highly differentiated localizations revealed by quantitative ultrastructural immunocytochemistry. Neuron (1995) 15:711-20. doi:10.1016/0896-6273(95)90158-2

59. Rothstein JD, Martin L, Levey AI, Dykes-Hoberg M, Jin L, Wu D, et al. Localization of neuronal and glial glutamate transporters. Neuron (1994) 13:713-25. doi:10.1016/0896-6273(94)90038-8

60. Hasegawa J, Obara T, Tanaka K, Tachibana M. High-density presynaptic transporters are required for glutamate removal from the first visual synapse. Neuron (2006) 50:63-74. doi:10.1016/j.neuron.2006.02.022

61. Wadiche JI, Jahr CE. Patterned expression of Purkinje cell glutamate transporters controls synaptic plasticity. Nat Neurosci (2005) 8:1329-34. doi:10. $1038 / \mathrm{nn} 1539$

62. Bergles DE, Jahr CE. Glial contribution to glutamate uptake at Schaffer collateral-commissural synapses in the hippocampus. J Neurosci (1998) 18:7709-16.

63. Rothstein JD, Dykes-Hoberg M, Pardo CA, Bristol LA, Jin L, Kuncl RW, et al. Knockout of glutamate transporters reveals a major role for astroglial transport in excitotoxicity and clearance of glutamate. Neuron (1996) 16:675-86. doi:10.1016/S0896-6273(00)80086-0

64. Lehre KP, Danbolt NC. The number of glutamate transporter subtype molecules at glutamatergic synapses: chemical and stereological quantification in young adult rat brain. J Neurosci (1998) 18:8751-7.

65. Ventura R, Harris KM. Three-dimensional relationships between hippocampal synapses and astrocytes. J Neurosci (1999) 19:6897-906.

66. Levy LM, Warr O, Attwell D. Stoichiometry of the glial glutamate transporter GLT-1 expressed inducibly in a Chinese hamster ovary cell line selected for low endogenous Na+-dependent glutamate uptake. J Neurosci (1998) 18: $9620-8$.
67. Zerangue N, Kavanaugh MP. Flux coupling in a neuronal glutamate transporter. Nature (1996) 383:634-7. doi:10.1038/383634a0

68. Schousboe A, Sickmann HM, Bak LK, Schousboe I, Jajo FS, Faek SA, et al. Neuron-glia interactions in glutamatergic neurotransmission: roles of oxidative and glycolytic adenosine triphosphate as energy source. $J$ Neurosci Res (2011) 89:1926-34. doi:10.1002/jnr.22746

69. Carroll RC, Beattie EC, von Zastrow M, Malenka RC. Role of AMPA receptor endocytosis in synaptic plasticity. Nat Rev Neurosci (2001) 2:315-24. doi:10.1038/35072500

70. Lissin DV, Gomperts SN, Carroll RC, Christine CW, Kalman D, Kitamura M, et al. Activity differentially regulates the surface expression of synaptic AMPA and NMDA glutamate receptors. Proc Natl Acad Sci U S A (1998) 95:7097-102. doi:10.1073/pnas.95.12.7097

71. Jarzylo LA, Man HY. Parasynaptic NMDA receptor signaling couples neuronal glutamate transporter function to AMPA receptor synaptic distribution and stability. J Neurosci (2012) 32:2552-63. doi:10.1523/JNEUROSCI.323711.2012

72. Chen H, Chan DC. Mitochondrial dynamics - fusion, fission, movement, and mitophagy - in neurodegenerative diseases. Hum Mol Genet (2009) 18:R169-76. doi:10.1093/hmg/ddp326

73. Cheng A, Hou Y, Mattson MP. Mitochondria and neuroplasticity. ASN Neuro (2010) 2:e00045. doi:10.1042/AN20100019

74. Kuiper JW, Pluk H, Oerlemans F, van Leeuwen FN, de Lange F, Fransen J, et al. Creatine kinase-mediated ATP supply fuels actin-based events in phagocytosis. PLoS Biol (2008) 6:e51. doi:10.1371/journal.pbio.0060051

75. MacAskill AF, Kittler JT. Control of mitochondrial transport and localization in neurons. Trends Cell Biol (2010) 20:102-12. doi:10.1016/j.tcb.2009.11.002

76. Overly CC, Rieff HI, Hollenbeck PJ. Organelle motility and metabolism in axons vs dendrites of cultured hippocampal neurons. J Cell Sci (1996) 109(Pt 5):971-80.

77. Macaskill AF, Rinholm JE, Twelvetrees AE, Arancibia-Carcamo IL, Muir J, Fransson A, et al. Mirol is a calcium sensor for glutamate receptor-dependent localization of mitochondria at synapses. Neuron (2009) 61:541-55. doi:10. 1016/j.neuron.2009.01.030

78. Fransson S, Ruusala A, Aspenstrom P. The atypical Rho GTPases Miro-1 and Miro-2 have essential roles in mitochondrial trafficking. Biochem Biophys Res Commun (2006) 344:500-10. doi:10.1016/j.bbrc.2006.03.163

79. Wang X, Schwarz TL. The mechanism of Ca2+ -dependent regulation of kinesin-mediated mitochondrial motility. Cell (2009) 136:163-74. doi:10. 1016/j.cell.2008.11.046

80. Fabricius C, Berthold CH, Rydmark M. Axoplasmic organelles at nodes of Ranvier. II. Occurrence and distribution in large myelinated spinal cord axons of the adult cat. J Neurocytol (1993) 22:941-54. doi:10.1007/ BF01218352

81. Zhang CL, Ho PL, Kintner DB, Sun D, Chiu SY. Activity-dependent regulation of mitochondrial motility by calcium and $\mathrm{Na} / \mathrm{K}$-ATPase at nodes of Ranvier of myelinated nerves. J Neurosci (2010) 30:3555-66. doi:10.1523/JNEUROSCI. 4551-09.2010

82. Courchet J, Lewis TL Jr, Lee S, Courchet V, Liou DY, Aizawa S, et al. Terminal axon branching is regulated by the LKB1-NUAK1 kinase pathway via presynaptic mitochondrial capture. Cell (2013) 153:1510-25. doi:10.1016/j.cell.2013.05. 021

83. Yi M, Weaver D, Hajnoczky G. Control of mitochondrial motility and distribution by the calcium signal: a homeostatic circuit. J Cell Biol (2004) 167:661-72. doi:10.1083/jcb.200406038

84. Lee CW, Peng HB. Mitochondrial clustering at the vertebrate neuromuscular junction during presynaptic differentiation. J Neurobiol (2006) 66:522-36. doi: $10.1002 /$ neu. 20245

85. Ferreira JM, Burnett AL, Rameau GA. Activity-dependent regulation of surface glucose transporter-3. J Neurosci (2011) 31:1991-9. doi:10.1523/JNEUROSCI. $1850-09.2011$

86. Magi S, Lariccia V, Castaldo P, Arcangeli S, Nasti AA, Giordano A, et al. Physical and functional interaction of NCX1 and EAAC1 transporters leading to glutamate-enhanced ATP production in brain mitochondria. PLoS One (2012) 7:e34015. doi:10.1371/journal.pone.0034015

87. Baltan S, Murphy SP, Danilov CA, Bachleda A, Morrison RS. Histone deacetylase inhibitors preserve white matter structure and function during ischemia by conserving ATP and reducing excitotoxicity. J Neurosci (2011) 31:3990-9. doi:10.1523/JNEUROSCI.5379-10.2011 
88. Del Rio P, Montiel T, Chagoya V, Massieu L. Exacerbation of excitotoxic neuronal death induced during mitochondrial inhibition in vivo: relation to energy imbalance or ATP depletion? Neuroscience (2007) 146:1561-70. doi:10.1016/j.neuroscience.2007.03.024

89. Nicholls DG, Budd SL. Mitochondria and neuronal glutamate excitotoxicity. Biochim Biophys Acta (1998) 1366:97-112. doi:10.1016/S0005-2728(98) 00123-6

90. Nicholls DG, Johnson-Cadwell L, Vesce S, Jekabsons M, Yadava N. Bioenergetics of mitochondria in cultured neurons and their role in glutamate excitotoxicity. J Neurosci Res (2007) 85:3206-12. doi:10.1002/jnr.21290

91. Mahadik SP, Bharucha VA, Stadlin A, Ortiz A, Karpiak SE. Loss and recovery of activities of alpha+ and alpha isozymes of $(\mathrm{Na}(+)+\mathrm{K}+)$-ATPase in cortical focal ischemia: GM1 ganglioside protects plasma membrane structure and function. J Neurosci Res (1992) 32:209-20. doi:10.1002/jnr.490320210

92. Mrsic-Pelcic J, Pelcic G, Vitezic D, Antoncic I, Filipovic T, Simonic A, et al. Hyperbaric oxygen treatment: the influence on the hippocampal superoxide dismutase and $\mathrm{Na}+, \mathrm{K}+-$ ATPase activities in global cerebral ischemia-exposed rats. Neurochem Int (2004) 44:585-94. doi:10.1016/j.neuint.2003.10.004

93. Culmsee C, Monnig J, Kemp BE, Mattson MP. AMP-activated protein kinase is highly expressed in neurons in the developing rat brain and promotes neuronal survival following glucose deprivation. J Mol Neurosci (2001) 17:45-58. doi:10.1385/JMN:17:1:45

94. Harada S, Fujita-Hamabe W, Tokuyama S. The importance of regulation of blood glucose levels through activation of peripheral 5'-AMP-activated protein kinase on ischemic neuronal damage. Brain Res (2010) 1351:254-63. doi:10.1016/j.brainres.2010.06.052

95. Wang P, Xu TY, Guan YF, Tian WW, Viollet B, Rui YC, et al. Nicotinamide phosphoribosyltransferase protects against ischemic stroke through SIRT1dependent adenosine monophosphate-activated kinase pathway. Ann Neurol (2011) 69:360-74. doi:10.1002/ana.22236

96. Li J, Zeng Z, Viollet B, Ronnett GV, McCullough LD. Neuroprotective effects of adenosine monophosphate-activated protein kinase inhibition and gene deletion in stroke. Stroke (2007) 38:2992-9. doi:10.1161/STROKEAHA.107.490904

97. McCullough LD, Zeng Z, Li H, Landree LE, McFadden J, Ronnett GV. Pharmacological inhibition of AMP-activated protein kinase provides neuroprotection in stroke. J Biol Chem (2005) 280:20493-502. doi:10.1074/jbc.M409985200

98. Ishii K, Sasaki H, Kono AK, Miyamoto N, Fukuda T, Mori E. Comparison of gray matter and metabolic reduction in mild Alzheimer's disease using FDGPET and voxel-based morphometric MR studies. Eur J Nucl Med Mol Imaging (2005) 32:959-63. doi:10.1007/s00259-004-1740-5

99. Sakamoto S, Ishii K, Sasaki M, Hosaka K, Mori T, Matsui M, et al. Differences in cerebral metabolic impairment between early and late onset types of Alzheimer's disease. J Neurol Sci (2002) 200:27-32. doi:10.1016/S0022510X(02)00114-4

100. Foster NL, Chase TN, Mansi L, Brooks R, Fedio P, Patronas NJ, et al. Cortical abnormalities in Alzheimer's disease. Ann Neurol (1984) 16:649-54. doi:10.1002/ana.410160605

101. Friedland RP, Budinger TF, Ganz E, Yano Y, Mathis CA, Koss B, et al. Regional cerebral metabolic alterations in dementia of the Alzheimer type: positron emission tomography with [18F]fluorodeoxyglucose. J Comput Assist Tomogr (1983) 7:590-8. doi:10.1097/00004728-198308000-00003

102. Minoshima S, Giordani B, Berent S, Frey KA, Foster NL, Kuhl DE. Metabolic reduction in the posterior cingulate cortex in very early Alzheimer's disease. Ann Neurol (1997) 42:85-94. doi:10.1002/ana.410420114

103. Simpson IA, Chundu KR, Davies-Hill T, Honer WG, Davies P. Decreased concentrations of GLUT1 and GLUT3 glucose transporters in the brains of patients with Alzheimer's disease. Ann Neurol (1994) 35:546-51. doi:10.1002/ ana.410350507

104. Jin N, Qian W, Yin X, Zhang L, Iqbal K, Grundke-Iqbal I, et al. CREB regulates the expression of neuronal glucose transporter 3: a possible mechanism related to impaired brain glucose uptake in Alzheimer's disease. Nucleic Acids Res (2013) 41:3240-56. doi:10.1093/nar/gks1227

105. Jornayvaz FR, Shulman GI. Regulation of mitochondrial biogenesis. Essays Biochem (2010) 47:69-84. doi:10.1042/bse0470069

106. Lu J, Wu DM, Zheng YL, Hu B, Zhang ZF, Shan Q, et al. Quercetin activates AMP-activated protein kinase by reducing PP2C expression protecting old mouse brain against high cholesterol-induced neurotoxicity. J Pathol (2010) 222:199-212. doi:10.1002/path.2754
107. Trushina E, Nemutlu E, Zhang S, Christensen T, Camp J, Mesa J, et al. Defects in mitochondrial dynamics and metabolomic signatures of evolving energetic stress in mouse models of familial Alzheimer's disease. PLoS One (2012) 7:e32737. doi:10.1371/journal.pone.0032737

108. Calkins MJ, Manczak M, Mao P, Shirendeb U, Reddy PH. Impaired mitochondrial biogenesis, defective axonal transport of mitochondria, abnormal mitochondrial dynamics and synaptic degeneration in a mouse model of Alzheimer's disease. Hum Mol Genet (2011) 20:4515-29. doi:10.1093/hmg/ ddr381

109. Cho S, Szeto HH, Kim E, Kim H, Tolhurst AT, Pinto JT. A novel cell-permeable antioxidant peptide, SS31, attenuates ischemic brain injury by down-regulating CD36. J Biol Chem (2007) 282:4634-42. doi:10.1074/jbc.M609388200

110. Choi SW, Gerencser AA, Ng R, Flynn JM, Melov S, Danielson SR, et al. No consistent bioenergetic defects in presynaptic nerve terminals isolated from mouse models of Alzheimer's disease. J Neurosci (2012) 32:16775-84. doi:10.1523/JNEUROSCI.2414-12.2012

111. Iijima-Ando K, Sekiya M, Maruko-Otake A, Ohtake Y, Suzuki E, Lu B, et al. Loss of axonal mitochondria promotes tau-mediated neurodegeneration and Alzheimer's disease-related tau phosphorylation cia PAR-1. PLoS Genet (2012) 8:e1002918. doi:10.1371/journal.pgen.1002918

112. Polymeropoulos MH, Lavedan C, Leroy E, Ide SE, Dehejia A, Dutra A, et al. Mutation in the alpha-synuclein gene identified in families with Parkinson's disease. Science (1997) 276:2045-7. doi:10.1126/science.276.5321.2045

113. Martin LJ, Pan Y, Price AC, Sterling W, Copeland NG, Jenkins NA, et al. Parkinson's disease alpha-synuclein transgenic mice develop neuronal mitochondrial degeneration and cell death. J Neurosci (2006) 26:41-50. doi:10.1523/ JNEUROSCI.4308-05.2006

114. Xie W, Chung KK. Alpha-synuclein impairs normal dynamics of mitochondria in cell and animal models of Parkinson's disease. J Neurochem (2012) 122:404-14. doi:10.1111/j.1471-4159.2012.07769.x

115. Bonifati V, Rizzu P, van Baren MJ, Schaap O, Breedveld GJ, Krieger E, et al. Mutations in the DJ-1 gene associated with autosomal recessive early-onset parkinsonism. Science (2003) 299:256-9. doi:10.1126/science.1077209

116. Kitada T, Asakawa S, Hattori N, Matsumine H, Yamamura Y, Minoshima S, et al. Mutations in the parkin gene cause autosomal recessive juvenile parkinsonism. Nature (1998) 392:605-8. doi:10.1038/33416

117. Valente EM, Abou-Sleiman PM, Caputo V, Muqit MM, Harvey K, Gispert S, et al. Hereditary early-onset Parkinson's disease caused by mutations in PINK1. Science (2004) 304:1158-60. doi:10.1126/science.1096284

118. Norremolle A, Riess O, Epplen JT, Fenger K, Hasholt L, Sorensen SA. Trinucleotide repeat elongation in the Huntingtin gene in Huntington disease patients from 71 Danish families. Hum Mol Genet (1993) 2:1475-6. doi:10.1093/hmg/2.9.1475

119. Stoessl AJ, Martin WR, Clark C, Adam MJ, Ammann W, Beckman JH, et al. PET studies of cerebral glucose metabolism in idiopathic torticollis. Neurology (1986) 36:653-7. doi:10.1212/WNL.36.5.653

120. Browne SE, Bowling AC, MacGarvey U, Baik MJ, Berger SC, Muqit MM, et al. Oxidative damage and metabolic dysfunction in Huntington's disease: selective vulnerability of the basal ganglia. Ann Neurol (1997) 41:646-53. doi:10.1002/ana.410410514

121. Gu M, Gash MT, Mann VM, Javoy-Agid F, Cooper JM, Schapira AH. Mitochondrial defect in Huntington's disease caudate nucleus. Ann Neurol (1996) 39:385-9. doi:10.1002/ana.410390317

122. Shirendeb UP, Calkins MJ, Manczak M, Anekonda V, Dufour B, McBride JL, et al. Mutant Huntingtin's interaction with mitochondrial protein Drp1 impairs mitochondrial biogenesis and causes defective axonal transport and synaptic degeneration in Huntington's disease. Hum Mol Genet (2012) 21:406-20. doi:10.1093/hmg/ddr475

123. Weydt P, Soyal SM, Gellera C, Didonato S, Weidinger C, Oberkofler H, et al. The gene coding for PGC-1alpha modifies age at onset in Huntington's disease. Mol Neurodegener (2009) 4:3. doi:10.1186/1750-1326-4-3

124. Shin JH, Ko HS, Kang H, Lee Y, Lee YI, Pletinkova O, et al. PARIS (ZNF746) repression of PGC-1alpha contributes to neurodegeneration in Parkinson's disease. Cell (2011) 144:689-702. doi:10.1016/j.cell.2011.02.010

125. Zheng B, Liao Z, Locascio JJ, Lesniak KA, Roderick SS, Watt ML, et al. PGC-lalpha, a potential therapeutic target for early intervention in Parkinson's disease. Sci Transl Med (2010) 2:52ra73. doi:10.1126/scitranslmed. 3001059 
126. Tsunemi T, La Spada AR. PGC-1alpha at the intersection of bioenergetics regulation and neuron function: from Huntington's disease to Parkinson's disease and beyond. Prog Neurobiol (2012) 97:142-51. doi:10.1016/j.pneurobio.2011. 10.004

127. Warden D. Military TBI during the Iraq and Afghanistan wars. J Head Trauma Rehabil (2006) 21:398-402. doi:10.1097/00001199-200609000-00004

128. McKee AC, Cantu RC, Nowinski CJ, Hedley-Whyte ET, Gavett BE, Budson $\mathrm{AE}$, et al. Chronic traumatic encephalopathy in athletes: progressive tauopathy after repetitive head injury. J Neuropathol Exp Neurol (2009) 68:709-35. doi:10.1097/NEN.0b013e3181a9d503

129. Omalu BI, DeKosky ST, Minster RL, Kamboh MI, Hamilton RL, Wecht CH. Chronic traumatic encephalopathy in a National Football League player. Neurosurgery (2005) 57:128-34. doi:10.1227/01.NEU.0000163407.92769.ED

130. Goodman JC, Valadka AB, Gopinath SP, Uzura M, Robertson CS. Extracellular lactate and glucose alterations in the brain after head injury measured by microdialysis. Crit Care Med (1999) 27:1965-73. doi:10.1097/00003246199909000-00041

131. Siesjo BK. Pathophysiology and treatment of focal cerebral ischemia. Part I: pathophysiology. J Neurosurg (1992) 77:169-84. doi:10.3171/jns.1992.77.2. 0169

132. Tavazzi B, Signoretti S, Lazzarino G, Amorini AM, Delfini R, Cimatti M, et al. Cerebral oxidative stress and depression of energy metabolism correlate with severity of diffuse brain injury in rats. Neurosurgery (2005) 56:582-9. doi:10.1227/01.NEU.0000156715.04900.E6

133. Obrist WD, Langfitt TW, Jaggi JL, Cruz J, Gennarelli TA. Cerebral blood flow and metabolism in comatose patients with acute head injury. Relationship to intracranial hypertension. J Neurosurg (1984) 61:241-53.

134. Arun P, Abu-Taleb R, Oguntayo S, Wang Y, Valiyaveettil M, Long J, et al. Acute mitochondrial dysfunction after blast exposure: potential role of mitochondrial glutamate oxaloacetate transaminase. J Neurotrauma (2013) 30(19):1645-51. doi:10.1089/neu.2012.2834

135. Singleton RH, Zhu J, Stone JR, Povlishock JT. Traumatically induced axotomy adjacent to the soma does not result in acute neuronal death. J Neurosci (2002) 22:791-802.

136. Young W. Role of calcium in central nervous system injuries. J Neurotrauma (1992) 9(Suppl 1):S9-25.

137. Leung AW, Halestrap AP. Recent progress in elucidating the molecular mechanism of the mitochondrial permeability transition pore. Biochim Biophys Acta (2008) 1777:946-52. doi:10.1016/j.bbabio.2008.03.009

138. Fink MP. Bench-to-bedside review: cytopathic hypoxia. Crit Care (2002) 6:491-9. doi:10.1186/cc1824

139. Wada K, Chatzipanteli K, Kraydieh S, Busto R, Dietrich WD. Inducible nitric oxide synthase expression after traumatic brain injury and neuroprotection with aminoguanidine treatment in rats. Neurosurgery (1998) 43:1427-36. doi:10.1227/00006123-199812000-00096

140. Petrov T, Underwood BD, Braun B, Alousi SS, Rafols JA. Upregulation of iNOS expression and phosphorylation of eIF-2alpha are paralleled by suppression of protein synthesis in rat hypothalamus in a closed head trauma model. $J$ Neurotrauma (2001) 18:799-812. doi:10.1089/089771501316919166

141. Sharma P, Benford B, Li ZZ, Ling GS. Role of pyruvate dehydrogenase complex in traumatic brain injury and Measurement of pyruvate dehydrogenase enzyme by dipstick test. J Emerg Trauma Shock (2009) 2:67-72. doi:10.4103/0974-2700.50739

142. Xing G, Ren M, Watson WD, O’Neill JT, Verma A. Traumatic brain injuryinduced expression and phosphorylation of pyruvate dehydrogenase: a mechanism of dysregulated glucose metabolism. Neurosci Lett (2009) 454:38-42. doi:10.1016/j.neulet.2009.01.047

143. Barr TL, Conley YP. Poly(ADP-ribose) polymerase-1 and its clinical applications in brain injury. J Neurosci Nurs (2007) 39:278-84. doi:10.1097/01376517200710000-00004

144. LaPlaca MC, Zhang J, Raghupathi R, Li JH, Smith F, Bareyre FM, et al. Pharmacologic inhibition of poly(ADP-ribose) polymerase is neuroprotective following traumatic brain injury in rats. J Neurotrauma (2001) 18:369-76. doi:10.1089/089771501750170912

145. Won SJ, Choi BY, Yoo BH, Sohn M, Ying W, Swanson RA, et al. Prevention of traumatic brain injury-induced neuron death by intranasal delivery of nicotinamide adenine dinucleotide. J Neurotrauma (2012) 29:1401-9. doi:10.1089/neu.2011.2228

Conflict of Interest Statement: The authors declare that the research was conducted in the absence of any commercial or financial relationships that could be construed as a potential conflict of interest.

Received: 29 August 2013; accepted: 26 November 2013; published online: 11 December 2013.

Citation: Khatri N and Man H-Y (2013) Synaptic activity and bioenergy homeostasis: implications in brain trauma and neurodegenerative diseases. Front. Neurol. 4:199. doi: 10.3389/fneur.2013.00199

This article was submitted to Neurotrauma, a section of the journal Frontiers in Neurology.

Copyright (c) 2013 Khatri and Man. This is an open-access article distributed under the terms of the Creative Commons Attribution License (CC BY). The use, distribution or reproduction in other forums is permitted, provided the original author(s) or licensor are credited and that the original publication in this journal is cited, in accordance with accepted academic practice. No use, distribution or reproduction is permitted which does not comply with these terms. 